\title{
Construction of an MRI-based decision tree to differentiate autoimmune and autoinflammatory inner ear disease from chronic otomastoiditis with sensorineural hearing loss
}

\section{Boeun Lee}

Ewha Womans University Medical Center

Yun Jung Bae ( $\nabla$ bae729@gmail.com )

Seoul National University Bundang Hospital

\section{Byung Yoon Choi}

Seoul National University Bundang Hospital

Hyojin Kim

Seoul National University Bundang Hospital

\section{Byung Se Choi}

Seoul National University Bundang Hospital Jae Hyoung Kim

Seoul National University Bundang Hospital

\section{Research Article}

Keywords: autoimmune and autoinflammatory inner ear disease, granulomatosis with polyangiitis, Cogan's syndrome, chronic otomastoiditis, sensorineural hearing loss, classification and regression tree

Posted Date: May 20th, 2021

DOl: https://doi.org/10.21203/rs.3.rs-515755/v1

License: (c) (i) This work is licensed under a Creative Commons Attribution 4.0 International License. Read Full License 


\section{Abstract}

Purpose Autoimmune and inner ear diseases (AIED/AID) are characterized by the symptom of sensorineural hearing loss (SNHL). To date, standardized diagnostic tools for AIED/AID are lacking, and clinically differentiating AIED/AID from chronic otomastoiditis (COM) with SNHL is challenging. This retrospective study aimed to construct an MRI-based decision tree using classification and regression tree (CART) analysis to distinguish AIED/AID from COM.

Methods In total, 67 patients were enrolled between January 2004 and October 2019, comprising AIED/AID $(n=18), \operatorname{COM}(n=24)$, and control groups $(n=25)$. All patients underwent 3 T temporal bone MRI, including post-contrast T1-weighted images (postT1WI) and post-contrast FLAIR images (postFLAIR). Two radiologists evaluated the presence of otomastoid effusion and inner ear contrast enhancement on MRI. A CART decision tree model was constructed using MRI features to differentiate AIED/AID from COM and control groups, and diagnostic performance was analyzed.

Results High-intensity bilateral effusion (61.1\%) and inner ear enhancement (postFLAIR, 93.8\%; postT1WI, $61.1 \%$ ) were the most common in the AIED/AID group. We constructed two CART decision tree models; the first used effusion amount as the first partitioning node and postT1WI-inner ear enhancement as the second node, whereas the second comprised two partitioning nodes with the degree of postFLAIRenhancement of the inner ear. The first and second models enabled distinction of AIED/AID from COM with high specificity (100\% and $94.3 \%$, respectively).

Conclusion The amount of effusion and degree of inner ear enhancement on MRI may facilitate the distinction between AIED/AID and COM with SNHL using decision tree models, thereby contributing to early diagnosis and intervention.

\section{Introduction}

Autoimmune inner ear disease (AIED) is a rare clinical condition characterized by progressive, bilateral, and often asymmetric sensorineural hearing loss (SNHL) ${ }^{1}$. In $15-30 \%$ of cases, AIED is secondary to systemic autoimmune diseases, including granulomatosis with polyangiitis (GPA) - previously termed Wegener's granulomatosis, Cogan's syndrome, systemic lupus erythematosus, or Sjögren's syndrome ${ }^{1,2}$. Autoinflammatory inner ear disease (AID) is a family of rare immune-mediated diseases. Conditions representative of AID include neonatal onset multisystem inflammatory disease (NOMID), chronic infantile neurological, cutaneous, and articular (CINCA) syndrome, and Bechet's disease ${ }^{3,4}$. Although the pathophysiologic features of AIED and AID are distinct, these conditions share similar clinical symptoms, such as bilateral $\mathrm{SNHL}^{3}$.

To date, standardized diagnostic tools for the diagnosis of AIED and AID (AIED/AID) are lacking. Currently, immune-mediated inner ear disease manifesting as cochleovestibular dysfunction is diagnosed by exclusion, depending upon clinical symptoms, laboratory tests, and/or steroid responsiveness. 
Distinguishing AIED/AID from chronic otomastoiditis (COM) can be challenging due to considerable overlap in clinical features, especially when COM presents with infectious labyrinthitis and SNHL. Cochlear dysfunction can occasionally be reversed by timely and appropriate medications in the case of GPA (a subset of AIED) ${ }^{5}$. In contrast, COM requires surgical treatment, and cochlear dysfunction is often irreversible; therefore, correct and timely diagnosis is critical. Nevertheless, serological and molecular genetic tests that enable definitive diagnosis are not always feasible in clinical settings and may not provide a conclusive diagnosis. Thus, in patients with SNHL and suspected AIED/AID who require diagnosis by exclusion, radiologic evaluation using magnetic resonance imaging (MRI) is mandatory to evaluate inner ear features. Nevertheless, there is a paucity of case reports on inner ear MRI findings in AIED/AID due to its low prevalence ${ }^{6-8}$.

In this study, we aimed to evaluate inner ear findings using high-resolution 3T MRI in patients clinically diagnosed with AIED/AID and to harness MRI findings to accurately differentiate between AIED/AID and COM by adopting classification and regression tree (CART) analysis. CART analysis is a form of binary recursive partitioning that employs non-parametric statistical methods ${ }^{9}$. CART models facilitate differential diagnosis due to ease of handling variables and simple interpretation in clinical practice ${ }^{10}$. The purpose of our study was to construct a decision tree based on MRI features in order to distinguish AIED/AID from COM with SNHL.

\section{Methods}

\section{Ethics approval}

The Institutional Review Board of our hospital approved this retrospective study (Seoul National University Bundang Hospital, approval no. 2003-598-101). The requirement for informed consent was waived by our IRB (Seoul National University Bundang Hospital, approval no. 2003-598-101). The methods and reporting of results are in accordance with the STROBE (Strengthening the Reporting of Observational Studies in Epidemiology) guidelines.

\section{Study population}

We searched the database in our tertiary referral institution for patients who were diagnosed with AIED/AID and received treatment between January 2004 and October 2019. Patients who received a confirmed diagnosis of AIED/AID via serologic, genetic, and/or pathologic tests and underwent highresolution temporal bone MRI on 3T were included in the AIED/AID group. The clinical diagnosis of AIED/AID was made based on previously reported criteria as follows. The diagnosis of GPA was based on clinical examination, serologic tests for anti-neutrophil cytoplasmic autoantibodies (ANCA), and/or histopathologic studies ${ }^{11-16}$. The diagnosis of CINCA syndrome was based on characteristic clinical features, such as a persistent urticarial rash concomitant with systemic inflammation signs and molecular analysis of the NLRP3 gene ${ }^{17,18}$. The diagnosis of Cogan's syndrome was made solely based on clinical findings such as bilateral ocular and vestibuloauditory symptoms without definite or specific diagnostic tests ${ }^{19}$. Patients who did not undergo temporal bone MRI, had motion or metallic artifacts on 
MRI, exhibited labyrinthitis ossificans on MRI and/or concurrent temporal bone computed tomography, and/or presented with systemic or temporal bone pathology other than AIED/AID were excluded.

Patients who underwent mastoidectomy for COM and preoperative high-resolution temporal bone MRI due to SNHL symptoms during the same study period were included in the COM group. The control group comprised patients who underwent high-resolution temporal bone MRI due to non-cochleovestibular symptoms such as hemifacial spasm or trigeminal neuralgia, non-specific dizziness, presbycusis, or any other symptomatology that was underpinned by etiology other than inner ear pathology.

\section{MRI protocol}

Temporal bone MRI was acquired using a 3T scanner (Achieva and Ingenia, Philips Healthcare, Best, the Netherlands) with a 16- or 32-channel SENSE head coil (Philips Healthcare). We acquired threedimensional (3D) heavily T2-weighted images (T2WI), two-dimensional (2D) pre-contrast T1-weighted images (T1WI), 3D pre-contrast fluid-attenuation inversion recovery images (preFLAIR), 3D post-contrast T1WI (postT1WI), and 3D post-contrast FLAIR images (postFLAIR). For contrast enhancement, 0.1 $\mathrm{mmol} / \mathrm{kg}$ of gadobutrol (Gadovist, Bayer Schering Pharma AG, Berlin, Germany) was intravenously injected as a bolus. PostT1WI and postFLAIR were scanned approximately 2 min and 7 min postinjection, respectively. Whole-brain T2WI and FLAIR were obtained in all patients to exclude other brain pathologies. Detailed parameters of each sequence are summarized in Table S1.

\section{MRI analyses}

Two neuroradiologists (Y.J.B. and B.S.C. with 11 and 21 years of experience, respectively) independently reviewed all temporal bone MRI scans. The radiologists were blinded to clinical diagnosis at the time of review. After independent evaluation, both radiologists reviewed the MRI scans by consensus and resolved any discrepancies. Based on previous reports of MRI findings in AIED/AID and COM with infectious labyrinthitis ${ }^{20}$, the following MRI features were evaluated: 1) presence, laterality, and amount of mastoid and middle ear effusion (Fig. S1A-D);2) presence and laterality of any MRI abnormalities in inner ear structures including the cochlea, vestibule, and semicircular canals including $2-1$ ) presence of hyperintensity in the inner ear on preFLAIR (Fig. S2), 2-2) presence and degree of enhancement in the inner ear on postFLAIR (Fig. S3A-D), and 2-3) presence of enhancement in the inner ear on postT1WI (Fig. S4A); 3) presence of enhancement of cranial nerves or dura on either postFLAIR or postT1WI (Fig. S4B-C); and 4) presence of enhancement of the nasopharynx, external auditory canal, and/or regional soft-tissue on postT1WI (Fig. S4D). Effusion was defined as soft-tissue filling the mastoid and middle ear cavity with T2-high and T1-low signal intensities. To assess the amount of effusion, the degree of opacification in the mastoid and middle ear was determined using four grades of increasing severity: $0 \%$, $<50 \%, 50-99 \%$, and $100 \%{ }^{20}$. The degree of inner ear postFLAIR-enhancement was scored according to four grades of increasing severity based on the work of Saat et al.: none, minimal, mild, and intense ${ }^{20}$. Ears were bilaterally evaluated in each patient. MRI features were considered positive if present on either side. 
We observed the presence of prominent nodular enhancement close to the external part of the basal turn of the cochlea at the round window (RW) level on postFLAIR and postT1WI (Fig. S5A-B). Based on a recent study by Dubrulle et al. ${ }^{21}$, we conjectured that this observation was equivalent to the "RW sign", which is a hypersignal area encompassing the RW on delayed contrast-enhanced FLAIR. Several patients presented with a linear hypersignal along the vestibular aqueduct (VA) on postFLAIR (Fig. S6). The presence of the RW sign on postFLAIR and postT1WI, and presence of VA enhancement on postFLAIR were evaluated by the two radiologists. Final decisions were reached by consensus.

\section{Statistical analyses}

Clinical characteristics and MRI findings were compared among groups using the Chi-square test and linear-by-linear association for categorical variables. For MRI findings, interobserver agreement between the two radiologists was calculated using Cohen's kappa ( $\mathrm{k}$ ) index as follows: poor agreement $(\mathrm{k} \leq 0.2)$, fair $(0.2<k \leq 0.4)$, moderate $(0.4<K \leq 0.6)$, good $(0.6<k \leq 0.8)$, and excellent $(0.8<K \leq 1.0){ }^{22,23}$. CART analysis was conducted to evaluate MRI features that were associated with superior differential diagnosis between AIED/AID and COM ${ }^{24}$. CART constructs a decision tree by splitting data repeatedly into two child nodes ${ }^{9,25}$. This tends to maximize class purity and homogeneity such that each child node is further classified into more homogeneous groups by selecting the variable that best splits the subgroup according to the algorithm ${ }^{25}$. We constructed two CART models in this study. In the first CART model, all evaluated MRI features were included. Variables related to inner ear abnormalities (i.e., contrast enhancement on postT1WI and postFLAIR), presence of the RW sign, and postFLAIR-enhancement of VA were selected in the second model to investigate MRI-based diagnostic performance. The diagnostic performance of the decision tree using the CART model was analyzed. Sensitivity, specificity, positive predictive value, and negative predictive value of the tree were calculated. CART analyses were performed with "rpart" of R statistical software (version 3.5.3., R Project for Statistical Computing, Vienna, Austria). Other statistical analyses were performed using MedCalc software (version 11.0). Statistical significance was set at $\mathrm{P}<0.05$.

\section{Results}

\section{Clinical characteristics}

In total, 67 patients were included in this study, comprising 18 patients in the AIED/AID group (8 males and 10 females, median age $=62$ years, age range $=45-66$ years $), 24$ patients in the COM group (11 males and 13 females, median age $=60$ years, age range $=57-64$ years), and 25 patients in the control group ( 6 males and 19 females; median age, $=61$ years; age range $=55-68$ years). Of patients in the AIED/AID group, 11 were diagnosed with GPA, 4 with CINCA syndrome, and 3 with Cogan's syndrome. All patients with GPA exhibited positive ANCA in serologic tests, and pathological confirmation was obtained for six of them via kidney and/or lung lesion biopsy $(n=3)$, nasopharyngeal lesion biopsy $(n=2)$, and nasal cavity lesion biopsy $(n=1)$. Of the four patients clinically diagnosed with CINCA syndrome, three were confirmed to have an NLRP3 variant based on genetic testing. 


\section{MRI findings according to clinical diagnosis}

All patients underwent heavily T2WI, pre-contrast T1WI, and postT1WI. PostFLAIR were obtained in 22 of 24 patients with COM, 16 of 18 patients with AIED/AID, and 12 of 25 control participants. PreFLAIR were unavailable in 18 of 24 patients with COM, 11 of 18 patients with AIED/AID, and 22 of 25 control participants.

Interobserver agreement was excellent for all MRI features $(k>0.8)$. Consensus MRI features according to clinical diagnosis are summarized in Table 1 and Table S2. Effusion in the mastoid and middle ear was present in all patients in the COM group (100\%) and in $72.2 \%$ of patients in the AIED/AID group. Effusion was absent in most control participants $(92.0 \%)$. The presence of effusion was predominantly unilateral in the COM group (87.5\%) and predominantly bilateral in the AIED/AID group (61.1\%). The amount of effusion was larger in the COM group than in the AIED/AID group ( $100 \%$ in 16 and 5 patients, respectively). 
Table 1

MRI findings according to clinical diagnosis

\begin{tabular}{|c|c|c|c|c|c|}
\hline & & $\begin{array}{l}\text { COM } \\
\text { group } \\
(n= \\
24)\end{array}$ & $\begin{array}{l}\text { AIED/AID } \\
\text { group } \\
(n=18)\end{array}$ & $\begin{array}{l}\text { Control } \\
\text { group } \\
(n= \\
25)\end{array}$ & $P$-value \\
\hline \multirow[t]{3}{*}{$\begin{array}{l}\text { Laterality of mastoid and middle ear } \\
\text { effusion }\end{array}$} & Absent & $0(0)$ & $5(27.8)$ & $\begin{array}{l}23 \\
(92.0)\end{array}$ & \multirow[t]{3}{*}{$<.0001^{\star}$} \\
\hline & Unilateral & $\begin{array}{l}21 \\
(87.5)\end{array}$ & $2(11.1)$ & $1(4.0)$ & \\
\hline & Bilateral & $\begin{array}{l}3 \\
(12.5)\end{array}$ & $11(61.1)$ & $1(4.0)$ & \\
\hline \multirow[t]{4}{*}{$\begin{array}{l}\text { Amount of mastoid and middle ear } \\
\text { effusion }\end{array}$} & $0 \%$ & $0(0)$ & $5(27.8)$ & $\begin{array}{l}25 \\
(100)\end{array}$ & \multirow[t]{4}{*}{$<.0001^{\star}$} \\
\hline & $<50 \%$ & $\begin{array}{l}3 \\
(12.5)\end{array}$ & $3(16.7)$ & $0(0)$ & \\
\hline & $50-99 \%$ & $\begin{array}{l}5 \\
(20.8)\end{array}$ & $5(27.8)$ & $0(0)$ & \\
\hline & $100 \%$ & $\begin{array}{l}16 \\
(66.7)\end{array}$ & $5(27.8)$ & $0(0)$ & \\
\hline \multirow[t]{2}{*}{$\begin{array}{l}\text { Presence of any abnormalities in the } \\
\text { inner ear }\end{array}$} & Absent & $\begin{array}{l}18 \\
(75.0)\end{array}$ & $0(0)$ & $\begin{array}{l}24 \\
(96.0)\end{array}$ & \multirow[t]{2}{*}{$<.0001^{*}$} \\
\hline & Present & $\begin{array}{l}6 \\
(25.0)\end{array}$ & $18(100)$ & $1(4.0)$ & \\
\hline \multirow[t]{3}{*}{ Location of inner ear pathology } & Absent & $\begin{array}{l}18 \\
(75.0)\end{array}$ & $0(0)$ & $\begin{array}{l}24 \\
(96.0)\end{array}$ & \multirow[t]{3}{*}{$<.0001^{\star}$} \\
\hline & $\begin{array}{l}\text { Cochlea } \\
\text { alone }\end{array}$ & $\begin{array}{l}4 \\
(16.7)\end{array}$ & $4(22.2)$ & $1(4.0)$ & \\
\hline & $\begin{array}{l}\text { More than } \\
\text { two } \\
\text { subsites }\end{array}$ & $2(8.3)$ & $14(77.8)$ & $0(0)$ & \\
\hline Laterality of inner ear pathology & Absent & $\begin{array}{l}18 \\
(75.0)\end{array}$ & $0(0)$ & $\begin{array}{l}24 \\
(96.0)\end{array}$ & $<.0001 *$ \\
\hline \multicolumn{6}{|l|}{ Data are presented as $\mathrm{n}(\%)$. } \\
\hline \multicolumn{6}{|c|}{$\begin{array}{l}\text { MRI, magnetic resonance imaging; COM, chronic otomastoiditis; AIED/AID, } \\
\text { autoimmune/autoinflammatory inner ear disease; preFLAIR, pre-contrast fluid-attenuated inversion } \\
\text { recovery image; postFLAIR, post-contrast fluid-attenuated inversion recovery image; postT1WI, post- } \\
\text { contrast T1-weighted image; RW sign, round window sign; VA, vestibular aqueduct }\end{array}$} \\
\hline \multicolumn{6}{|c|}{ * Statistical significance was set at $P<0.05$. } \\
\hline
\end{tabular}




\begin{tabular}{|c|c|c|c|c|c|}
\hline & & $\begin{array}{l}\text { COM } \\
\text { group } \\
(n= \\
24)\end{array}$ & $\begin{array}{l}\text { AlED/AID } \\
\text { group } \\
(n=18)\end{array}$ & $\begin{array}{l}\text { Control } \\
\text { group } \\
(n= \\
25)\end{array}$ & P-value \\
\hline & Unilateral & $2(8.3)$ & $2(11.1)$ & $0(0)$ & \\
\hline & Bilateral & $\begin{array}{l}4 \\
(16.7)\end{array}$ & $16(88.9)$ & $1(4.0)$ & \\
\hline Presence of preFLAIR hyperintensity & Absent & $\begin{array}{l}4 \\
(16.7)\end{array}$ & $0(0)$ & $\begin{array}{l}3 \\
(12.0)\end{array}$ & $0.005^{\star}$ \\
\hline & Present & $2(8.3)$ & $7(38.9)$ & $0(0)$ & \\
\hline & $\begin{array}{l}\text { Not } \\
\text { available }\end{array}$ & $\begin{array}{l}18 \\
(75.0)\end{array}$ & $11(61.1)$ & $\begin{array}{l}22 \\
(88.0)\end{array}$ & \\
\hline Presence of postFLAIR enhancement & Absent & $\begin{array}{l}16 \\
(66.7)\end{array}$ & $1(5.6)$ & $\begin{array}{l}11 \\
(44.0)\end{array}$ & $\begin{array}{l}< \\
0.0001 *\end{array}$ \\
\hline & Present & $\begin{array}{l}6 \\
(25.0)\end{array}$ & $15(83.3)$ & $1(4.0)$ & \\
\hline & $\begin{array}{l}\text { Not } \\
\text { available }\end{array}$ & $2(8.3)$ & $2(11.1)$ & $\begin{array}{l}13 \\
(52.0)\end{array}$ & \\
\hline Degree of postFLAIR enhancement & None & $\begin{array}{l}16 \\
(66.7)\end{array}$ & $2(11.1)$ & $\begin{array}{l}17 \\
(68.0)\end{array}$ & $<.0001 *$ \\
\hline & Minimal & $\begin{array}{l}5 \\
(20.8)\end{array}$ & $1(5.5)$ & $1(4.0)$ & \\
\hline & Mild & $1(4.2)$ & $2(11.1)$ & $0(0)$ & \\
\hline & Intensive & $0(0)$ & $12(66.8)$ & $0(0)$ & \\
\hline & $\begin{array}{l}\text { Not } \\
\text { available }\end{array}$ & $2(8.3)$ & $1(5.5)$ & $\begin{array}{l}7 \\
(28.0)\end{array}$ & \\
\hline Presence of postT1WI enhancement & Absent & $\begin{array}{l}24 \\
(100)\end{array}$ & $7(38.9)$ & $\begin{array}{l}25 \\
(100)\end{array}$ & $\begin{array}{l}< \\
0.0001 *\end{array}$ \\
\hline & Present & $0(0)$ & $11(61.1)$ & $0(0)$ & \\
\hline Presence of cranial nerve involvement & Absent & $\begin{array}{l}24 \\
(100)\end{array}$ & $15(83.3)$ & $\begin{array}{l}25 \\
(100)\end{array}$ & $0.0139 *$ \\
\hline Data are presented as $\mathrm{n}(\%)$ & & & & & \\
\hline $\begin{array}{l}\text { MRI, magnetic resonance imaging; CON } \\
\text { autoimmune/autoinflammatory inner e } \\
\text { recovery image; postFLAIR, post-contra } \\
\text { contrast T1-weighted image; RW sign, } r\end{array}$ & $\begin{array}{l}\text { ronic otom } \\
\text { sease; preF } \\
\text { id-attenua } \\
\text { window s }\end{array}$ & $\begin{array}{l}\text { iditis; AlE } \\
\text { 2, pre-cor } \\
\text { nversion } \\
\text { VA, vestil }\end{array}$ & $\begin{array}{l}\text { /AID, } \\
\text { ast fluid-a } \\
\text { covery ime } \\
\text { lar aquedu }\end{array}$ & puated in & rion \\
\hline
\end{tabular}




\begin{tabular}{|c|c|c|c|c|c|}
\hline & & $\begin{array}{l}\text { COM } \\
\text { group }\end{array}$ & $\begin{array}{l}\text { AIED/AID } \\
\text { group }\end{array}$ & $\begin{array}{l}\text { Control } \\
\text { group }\end{array}$ & $P$-value \\
\hline & & $\begin{array}{l}(n= \\
24)\end{array}$ & $(n=18)$ & $\begin{array}{l}(n= \\
25)\end{array}$ & \\
\hline & Present & $0(0)$ & $3(16.7)$ & $0(0)$ & \\
\hline Presence of dura involvement & Absent & $\begin{array}{l}23 \\
(95.8)\end{array}$ & $12(66.7)$ & $\begin{array}{l}25 \\
(100)\end{array}$ & $0.0009 *$ \\
\hline & Present & $1(4.2)$ & $6(33.3)$ & $0(0)$ & \\
\hline $\begin{array}{l}\text { Presence of nasopharynx, external } \\
\text { auditory canal, and regional soft-tissue }\end{array}$ & Absent & $\begin{array}{l}23 \\
(95.85)\end{array}$ & $9(50)$ & $\begin{array}{l}25 \\
(100)\end{array}$ & $<.0001 *$ \\
\hline & Present & $1(4.2)$ & $9(50)$ & $0(0)$ & \\
\hline Presence of RW sign on postFLAIR & Absent & $\begin{array}{l}17 \\
(70.9)\end{array}$ & $5(27.8)$ & $17(68)$ & $0.0001 *$ \\
\hline & Present & $\begin{array}{l}5 \\
(20.8)\end{array}$ & $11(61.1)$ & $0(0)$ & \\
\hline & $\begin{array}{l}\text { Not } \\
\text { available }\end{array}$ & $2(8.3)$ & $2(11.1)$ & $8(32)$ & \\
\hline Presence of RW sign on postT1WI & Absent & $\begin{array}{l}22 \\
(91.7)\end{array}$ & $8(44.4)$ & $\begin{array}{l}25 \\
(100)\end{array}$ & $<.0001 *$ \\
\hline & Present & $2(8.3)$ & $10(55.6)$ & 0 & \\
\hline $\begin{array}{l}\text { Presence of VA enhancement on } \\
\text { postFLAIR }\end{array}$ & Absent & $\begin{array}{l}20 \\
(83.4)\end{array}$ & 7 (38.9) & $17(68)$ & $0.0001 *$ \\
\hline & Present & $2(8.3)$ & $9(50.0)$ & 0 & \\
\hline & $\begin{array}{l}\text { Not } \\
\text { available }\end{array}$ & $2(8.3)$ & $2(11.1)$ & $8(32)$ & \\
\hline Data are presented as $\mathrm{n}(\%)$. & & & & & \\
\hline $\begin{array}{l}\text { MRI, magnetic resonance imaging; COM } \\
\text { autoimmune/autoinflammatory inner ea } \\
\text { recovery image; postFLAIR, post-contras } \\
\text { contrast T1-weighted image; RW sign, ro }\end{array}$ & $\begin{array}{l}\text { ronic otoma } \\
\text { sease; preFl } \\
\text { id-attenuate } \\
\text { I window sic }\end{array}$ & $\begin{array}{l}\text { iditis; AlE } \\
\text { 2, pre-con } \\
\text { version } \\
\text { VA, vestib }\end{array}$ & $\begin{array}{l}\text { /AID, } \\
\text { ast fluid-a } \\
\text { covery ime } \\
\text { lar aquedu }\end{array}$ & $\begin{array}{l}\text { nuated in } \\
; \text { postT1 }\end{array}$ & rion \\
\hline t & & & & & \\
\hline
\end{tabular}

All patients in the AIED/AID group (100\%) presented with abnormal findings on either side of inner ear structures. Division of inner ear structures into the cochlea, vestibule, and semicircular canal revealed that $77.8 \%$ of the AIED/AID group presented with involvement of more than two subsites, and $88.9 \%$ presented with bilateral involvement of inner ear structures. The prevalence of preFLAIR hyperintensity and postFLAIR-enhancement was significantly higher in the AIED/AID group ( $100 \%$ and $93.8 \%$, respectively) 
than in the COM group (33.3\% and $27.3 \%$, respectively). The degree of postFLAIR-enhancement was minimal to mild in all patients with COM and was significantly greater (intensive in $66.8 \%$ ) in patients with AIED/AID. The presence of postT1WI-enhancement in the inner ear was observed exclusively in the AIED/AID group (61.1\%). No inner ear postT1WI-enhancement was observed in the COM and control groups.

An ancillary but notable finding was the presence of cranial nerve enhancement in 3 of 18 patients in the AIED/AID group. No such observations were noted in the COM or control groups. The frequency of cranial nerve enhancement was significantly higher in the AIED/AID group than in the COM and control groups $(P=0.014)$. Abnormal dural enhancement was significantly greater in the AIED/AID group $(33.3 \%)$ than in the $\operatorname{COM}(4.2 \%)$ and control groups ( $0 \%)$. Abnormal cranial nerve enhancement was observed in 2 of 4 patients (50.0\%) with CINCA syndrome and 1 of 11 patients (9.09\%) with GPA. The frequency of dural enhancement was significantly higher in patients with GPA (45.5\%) than Cogan's or CINCA syndromes. One of three patients with Cogan's syndrome and one patient in the COM group presented with abnormal dural enhancement. The prevalence of abnormal enhancement in the adjacent nasopharynx, external auditory canal, and regional soft-tissue area was significantly higher in the AIED/AID group (50\%), especially in patients with GPA (7 of 11 patients) than other two subsets.

The frequency of the RW sign in postFLAIR and postT1WI was significantly higher in the AIED/AID group than in the COM group. None of the control participants presented with the RW sign. VA enhancement on postFLAIR was present in 9 of 16 patients with AID/AIED; this prevalence was significantly higher than that in the COM group (2 of 22 patients).

\section{MRI-based decision tree}

We constructed a first model using all MRI features (summarized in Table 1). In this decision tree model (Fig. 1A), the amount of effusion in the mastoid and middle ear cavities was used as the first partitioning node. Of the 67 patients, 37 (55.2\%) presented with > 50\% opacification of the effusion. For these patients, the next branching node was the presence of inner ear enhancement on postT1WI. Of these 37 patients, 27 (73.0\%) did not present with postT1WI-enhancement in the inner ear; 24 of these 27 patients (88.9\%) were in the COM group and three $(11.1 \%)$ were in the AID/AIED group. Of the 37 patients, 10 (27.0\%) who presented with inner ear enhancement on postT1WI were in the AID/AIED group (100\%). The sensitivity, specificity, positive predictive value, and negative predictive value for each clinical diagnosis in the first tree model are presented in Table 2. 
Table 2

Diagnostic performance of the two decision-making trees

\begin{tabular}{|c|c|c|c|c|}
\hline & $\begin{array}{l}\text { SN (\%) } \\
(95 \% \mathrm{Cl})\end{array}$ & $\begin{array}{l}\mathrm{SP}(\%) \\
(95 \% \mathrm{Cl})\end{array}$ & $\begin{array}{l}\text { PPV (\%) } \\
(95 \% \mathrm{Cl})\end{array}$ & $\begin{array}{l}\text { NPV (\%) } \\
(95 \% \mathrm{Cl})\end{array}$ \\
\hline \multicolumn{5}{|l|}{ The first decision-making tree ${ }^{a}$} \\
\hline \multirow{2}{*}{$\begin{array}{l}\text { (COM group) vs. (AIED/AID, control } \\
\text { groups) }\end{array}$} & 100 & 93 & 88.9 & 100 \\
\hline & $(0-100)$ & $\begin{array}{l}(38.8- \\
85.4)\end{array}$ & $\begin{array}{l}(60.5- \\
77.0)\end{array}$ & $(0-100)$ \\
\hline \multirow{2}{*}{$\begin{array}{l}\text { (AIED/AID group) vs. (COM, control } \\
\text { groups) }\end{array}$} & 55.6 & 100 & 100 & 86 \\
\hline & $\begin{array}{l}(32.6- \\
78.5)\end{array}$ & $(0-100)$ & $(0-100)$ & $(77-95)$ \\
\hline \multirow{2}{*}{$\begin{array}{l}\text { (Control group) vs. (COM, AIED/AID } \\
\text { groups) }\end{array}$} & 100 & 88.1 & 88.3 & 100 \\
\hline & $(0-100)$ & $\begin{array}{l}(78.3- \\
97.9)\end{array}$ & $(70-97)$ & $(0-100)$ \\
\hline \multicolumn{5}{|l|}{ The second decision-making tree ${ }^{b}$} \\
\hline \multirow{2}{*}{$\begin{array}{l}\text { (COM group) vs. (AIED/AID, control } \\
\text { groups) }\end{array}$} & 22.7 & 91.3 & 71.4 & 55.3 \\
\hline & $\begin{array}{l}(52.1- \\
40.2)\end{array}$ & $(80.0-100)$ & $(38.0-100)$ & $\begin{array}{l}(39.4- \\
71.1)\end{array}$ \\
\hline \multirow{2}{*}{$\begin{array}{l}\text { (AIED/AID group) vs. (COM, control } \\
\text { groups) }\end{array}$} & 40 & 94.5 & 66.7 & 92.8 \\
\hline & $(0-83.0)$ & $(92.7-100)$ & $(13.3-100)$ & $(85.1-100)$ \\
\hline \multirow{2}{*}{$\begin{array}{l}\text { (Control group) vs. (COM, AIED/AID } \\
\text { groups) }\end{array}$} & 94.4 & 33.3 & 48.6 & 90 \\
\hline & $(83.9-100)$ & $\begin{array}{l}(15.5- \\
51.1)\end{array}$ & $(32.0-65.1)$ & $(71.4-100)$ \\
\hline \multicolumn{5}{|c|}{$\begin{array}{l}\text { SN, sensitivity; SP, specificity; PPV, positive predictive value; NPV, negative predictive value; } \mathrm{Cl} \text {, } \\
\text { confidence interval; COM, chronic otomastoiditis; AIED/AID, autoimmune/autoinflammatory inner ear } \\
\text { disease. }\end{array}$} \\
\hline \multicolumn{5}{|c|}{$\begin{array}{l}\text { a The first decision-making tree used two nodes for the amount of effusion and presence of inner ear } \\
\text { enhancement on post-contrast T1-wegithed image. }\end{array}$} \\
\hline
\end{tabular}

The second tree model was constructed using variables related to inner ear enhancement, RW sign, and VA enhancement. In this second tree model (Fig. 1B), only the degree of postFLAIR-enhancement in the inner ear was maintained as both the first and second partitioning nodes. The degree of postFLAIR- 
enhancement in the inner ear was mild or intense in $16(23.9 \%)$ of the 67 patients, the majority of which belonged to the AIED/AID group (15 of 16 patients, 93.8\%). In contrast, 51 of the 67 patients (76.1\%) with absent or minimal degree of postFLAIR inner ear enhancement belonged to the COM or control groups. The sensitivity, specificity, positive predictive value, and negative predictive value for each clinical diagnosis in the second tree model are summarized in Table 2.

\section{Representative cases of CINCA syndrome}

Here, we present three rare cases of CINCA syndrome which exhibited distinct MRI features according to the degree of expression of NLRP3 variants. CINCA syndrome is a rare AIED with autosomal dominant inheritance ${ }^{3}$ and is linked with NLRP3 variants which cause hyper-activation of inflammasomes and excessive release of interleukin- ${ }^{3}$. Monocytes, which release interleukin-1, are distributed throughout the cochlear nerve and cochlear structure; hence, NLPR3 gene mutations affect the auditory nerve depending on the degree of expression.

\section{Case 1}

A 13-year-old male was diagnosed with full-blown CINCA due to a de novo variant of NLRP3 with high expressivity. Intense postFLAIR-enhancement was observed in the cochlea, vestibule, and semicircular canal, and strong enhancement involving the cochlear nerve was also noted (Fig. 2A).

\section{Case 2}

A 33-year-old female was diagnosed with DFNA34, a non-syndromic form of hearing loss due to an $N L R P 3$ variant with substantially lower expression. PostFLAIR revealed stronger postFLAIR-enhancement in the cochlear nerve than in the cochlea, although postFLAIR-enhancement in the cochlear nerve was also strong (Fig. 2B).

\section{Case 3}

A 38-year-old female was suspected of having AID with CINCA syndrome, but no detectable NLRP3 variant was observed. Mild postFLAIR-enhancement was observed in the cochlea, but no demonstrable enhancement of the cochlear nerve was noted (Fig. 2C).

\section{Discussion}

This study is the first to evaluate MRI findings in patients with AIED/AID and concomitant SNHL, including patients with GPA, CINCA syndrome, and Cogan's syndrome. We observed that the frequency of bilateral postFLAIR- and postT1WI-inner ear enhancements, RW sign, and VA enhancement was higher in patients with AIED/AID than in patients with COM and control participants. Further, the frequency of regional soft-tissue enhancement was significantly higher in patients with GPA than in other patients with AIED/AID. Our CART decision tree model demonstrated that the amount of bilateral effusion in the mastoid and middle ear cavity and presence and degree of inner ear enhancement on postFLAIR and 
postT1WI enabled differentiation of AIED/AID from COM accompanied by SNHL with high specificity. Our findings support the employment of this simple tree model to facilitate radiologic decision-making for patients with AIED/AID and COM.

There is a paucity of radiologic research on AIED/AID, with the exception of several case reports, and standardized diagnostic tools for inner ear involvement are lacking. Teszler et al. reported a case of GPA with bilateral otitis media and rapidly progressive SNHL; the patient presented with postT1WIenhancement in bilateral cochlear basal turns, which subsequently resolved with immunosuppressive therapy ${ }^{26}$. Yildirim et al. reported a case of GPA presenting with bilateral cochlear and leptomeningeal enhancement, which was in accordance with our findings ${ }^{27}$. Radiologic findings of Cogan's syndrome have been reported by Casselman et al. including obliteration of the intralabyrinthine fluid spaces with calcification formation and high signal intensity and enhancement of the cochlea and vestibule on preand post-contrast $\mathrm{T} 1 \mathrm{WI}{ }^{28}$.

Nevertheless, reports of relevant MRI findings are scarce and fail to distinguish AIED/AID from other etiologies such as labyrinthitis accompanied by COM. In patients with COM, dysfunction in sound transmission from the middle ear to inner ear results in conductive hearing loss. Patients with COM may also develop SNHL due to cochlear damage or altered sound wave transmission mechanisms in the ear 29. Thus, for cases of SNHL with COM in the absence of clinical signs of COM such as tympanic membrane perforation, distinguishing inner ear involvement due to AIED/AID from that due to COM is challenging.

In this context, we hypothesized that specific MRI findings could be used to differentiate between AIED/AID and COM. We therefore generated MRI-based decision trees to differentiate these two conditions. In our first tree model, the amount of effusion in the mastoid and middle ear cavities was used as the first partitioning node. Radiologic reports of mastoid or middle ear cavity effusion in patients with AIED/AID are lacking, but it is aware that the most frequent manifestations of COM are mastoid and middle ear cavity effusion ${ }^{30,31}$. Accordingly, our study demonstrated that the proportion of patients with effusion amount exceeding 50\% was higher in the COM group than in the AIED/AID group. Conversely, approximately half of the AIED/AID group presented with effusion exceeding $50 \%$, and when present, bilateral effusion was more frequent. The pathogenesis of COM involves dysfunction of ventilation of the middle ear cavity and mastoid air cells due to Eustachian tube impairment. Therefore, COM commonly manifests as a large amount of unilateral effusion and persistent inflammation of the middle ear or mastoid cavity ${ }^{32,33}$. AIED and AID are underscored by pathology of the inner ear but not middle ear; hence, the amount of effusion is smaller but frequency of bilateral effusion is higher than that in COM given the systemic nature of AIED/AID.

The second partition of the first tree model was postT1WI-enhancement in inner ear structures. The presence of postT1WI-enhancement predicted AIED/AID with high diagnostic performance. Indeed, cochlear enhancement has been reported in previous case studies of AIED ${ }^{34-38}$. This result was strongly associated with the partitioning nodes in the second tree model, which constituted postFLAIR- 
enhancement of inner ear structures; here, most patients in the AIED/AID group exhibited postFLAIRenhancement (93.8\%) with high intensity (80\%). In contrast, the frequency of postFLAIR-enhancement was lower in the COM group than in the AIED/AID group. These results could be due to the underlying pathogenesis of these diseases. It has been proposed that uncontrolled attack on inner ear proteins results in proinflammatory T-cell responses and autoantibody formation in AIED/AID ${ }^{3}$. In addition, lymphocytes activated by autoimmune responses cross the blood-labyrinthine barrier and reach the endolymphatic sac ${ }^{39}$. Accordingly, AIED and AID are frequently accompanied by SNHL at early stages, leading to active inflammation of the inner ear. Indeed, the occurrence and degree of inner ear enhancement and degree of symptoms were more frequent and severe in patients with AIED/AID than in patients with COM. In particular, postFLAIR is more sensitive to inner ear enhancement due to impairment of the blood-labyrinthine barrier ${ }^{40}$ given that postFLAIR is more sensitive to low concentrations of gadolinium contrast compared to postT1WI. In this regard, we observed intense enhancement on postFLAIR in the majority of patients with AIED/AID but in only one patient with COM, whereas postT1WIenhancement was present exclusively in the AIED/AID group.

The frequency of the RW sign on both postFLAIR and postT1WI was significantly higher in the AIED/AID group than in the COM group. Dubrulle et al. reported the use of the RW sign as a marker for perilymphatic fistula resulting in contrast pooling in the RW region ${ }^{21}$. Attye et al. reported that the RW sign was observed following obliteration of the RW due to inflammation ${ }^{41}$. We thus hypothesized that the presence of nodular enhancement at the RW on immediate postFLAIR and postT1WI could be due to significant inflammation at the RW level. Our results suggest that inflammation may be more severe in the inner ear and RW in patients with AIED/AID than in patients with COM due to increased permeability and diffusion of microtoxins into the inner ear ${ }^{29}$. Additionally, the frequency of VA enhancement on postFLAIR was significantly higher in the AIED/AID group. Given that the endolymphatic sac is associated with AIED pathogenesis ${ }^{39}$, VA enhancement on postFLAIR suggests more severe inflammation of the endolymphatic sac in AIED and AID than in COM-associated labyrinthitis.

We noted differences in the prevalence of MRI findings among AIED/AID subsets (Table S2). Abnormal enhancement involving the dura, nasopharynx, external auditory canal, and regional soft-tissue area were significantly more frequent in patients with GPA. Previously, diffuse meningeal enhancement and abnormal soft-tissue enhancement in the nasopharynx in patients with GPA have been reported ${ }^{42-45}$. In addition, the amount of effusion tended to be larger in patients with GPA than in those with Cogan's or CINCA syndrome, presumably due to Eustachian tube dysfunction resulting from soft-tissue involvement. Cranial nerve enhancement was noted in one of the patients with GPA, which verifies cranial nerve involvement and agrees with reports of cranial palsy in patients with GPA ${ }^{46,47}$. Patients with Cogan's syndrome exhibited intense bilateral inner ear enhancements, and one patient presented with dura and adjacent soft-tissue enhancements. Our findings are in accordance with previous reports indicating that Cogan's syndrome manifests with meningoencephalitis, cranial neuropathy, and inner ear enhancement on MRI ${ }^{34-37}$. Moreover, intense inner enhancement was observed in patients with CINCA syndrome. Abnormal cochlear nerve enhancement was dependent on the degree of NLRP3 gene mutations, in 
agreement with the findings of Behringer et al., who reported multiple cranial nerve enhancement and cochlear enhancement in a patient with CINCA syndrome ${ }^{38}$. Consequently, we speculate that subcategories of AIED/AID can be differentiated using specific MRI findings, but further studies are required to validate these results.

This study has several limitations. First, although we included patients diagnosed with AIED/AID from a nationwide tertiary referral hospital over a decade, the sample size was relatively small. However, the low prevalence of AIED/AID is a fundamental limiting factor in this regard. Further, the prevalence of GPA was higher than that of Cogan's or CINCA syndrome in the AIED/AID group, possibly due to the low prevalence of AIED/AID. Future multi-center studies with larger sample sizes are warranted. Second, we used different MRI machines and coils with different channels, which might affect the image quality. However, all machines were based on 3T, and despite the difference in the coils, interobserver agreement on the visual image analysis between the radiologists was excellent. Therefore, we believe that this difference had little effect on the results. Lastly, our study focused on radiologic differentiation between inner ear involvement by AIED/AID and COM. As such, we did not evaluate the relationship between MRI findings and clinical symptom severity or prognosis post-treatment. Future studies are warranted to verify clinicradiological associations in AIED/AID.

\section{Conclusions}

The amount of effusion, postT1WI- and postFLAIR-inner ear enhancement, RW sign and VA enhancement on postFLAIR and postT1WI may differentiate AIED/AID (including GPA, Cogan's and CINCA syndromes) from COM presenting with SNHL. Our high-resolution MRI-based CART model may be a useful tool for diagnosing and treating patients with AIED/AID and COM that present with similar clinical symptoms.

\section{Declarations}

\section{Availability of data and material}

Data are only available upon request, and before the request, data cannot be shared publicly by the regulation of Institutional Review Board of Seoul National University Bundang Hospital, because data may contain potentially identifying or sensitive patient information. For researchers who may wish to have access to data of this study, please contact via the following e-mail and send data inquiry: serenaaug@snubh.org (Research Support, Institutional Review Board of Seoul National University Bundang Hospital).

\section{Authors' contributions}

Boeun Lee, MD, Yun Jung Bae, MD, PhD, Byung Yoon Choi, MD, PhD, Hyojin Kim, MD, PhD, Byung Se Choi, MD, PhD, Jae Hyoung Kim, MD, PhD

Conception or design of the work: B.L., Y.J.B., B.Y.C. 
Acquisition, analysis, and interpretation of data for the work: B.L., Y.J.B., B.Y.C., H.K., B.S.C.

Drafting the work: B.L., Y.J.B., B.Y.C.

Revising the work critically for important intellectual content: B.L., Y.J.B., B.Y.C., H.K., B.S.C., J.H.K.

Final approval of the work: B.L., Y.J.B., B.Y.C., H.K., B.S.C., J.H.K.

\section{References}

1 Ciorba, A. et al. Autoimmune inner ear disease (AIED): A diagnostic challenge. International journal of immunopathology and pharmacology 32, 2058738418808680, doi:10.1177/2058738418808680 (2018).

2 Greco, A. et al. Cogan's syndrome: an autoimmune inner ear disease. Autoimmunity reviews 12, 396400, doi:10.1016/j.autrev.2012.07.012 (2013).

3 Vambutas, A. \& Pathak, S. AAO: Autoimmune and Autoinflammatory (Disease) in Otology: What is New in Immune-Mediated Hearing Loss. Laryngoscope investigative otolaryngology 1, 110-115, doi:10.1002/lio2.28 (2016).

4 Savic, S. et al. Autoimmune-autoinflammatory rheumatoid arthritis overlaps: a rare but potentially important subgroup of diseases. RMD open 3, e000550, doi:10.1136/rmdopen-2017-000550 (2017).

5 Yoshida, N. et al. Reversible cochlear function with ANCA-associated vasculitis initially diagnosed by otologic symptoms. Otology \& neurotology : official publication of the American Otological Society, American Neurotology Society [and] European Academy of Otology and Neurotology 35, 114-120, doi:10.1097/mao.0000000000000175 (2014).

6 Fayyaz, B. \& Upreti, S. Autoimmune inner ear disease secondary to Hashimoto's thyroiditis: a case report. Journal of community hospital internal medicine perspectives 8, 227-229, doi:10.1080/20009666.2018.1503917 (2018).

7 Susac, J. O. et al. MRI findings in Susac's syndrome. Neurology 61, 1783-1787, doi:10.1212/01.wnl.0000103880.29693.48 (2003).

8 Marsili, M. et al. Autoimmune sensorineural hearing loss as presenting manifestation of paediatric Behçet disease responding to adalimumab: a case report. Italian journal of pediatrics 42,81 , doi:10.1186/s13052-016-0291-2 (2016).

9 Breiman, L., Friedman, J. H., Olshen, R. A. \& Stone, C. J. J. I. G. Classification and regression trees. Belmont, CA: Wadsworth. 432, 151-166 (1984). 
10 Timofeev, R. J. H. U., Berlin. Classification and regression trees (CART) theory and applications. 140 (2004).

11 Fahey, J. L., Leonard, E., Churg, J. \& Godman, G. Wegener's granulomatosis. The American journal of medicine 17, 168-179, doi:10.1016/0002-9343(54)90255-7 (1954).

12 Anderson, G. et al. Wegener's granuloma. A series of 265 British cases seen between 1975 and 1985. A report by a sub-committee of the British Thoracic Society Research Committee. The Quarterly journal of medicine $83,427-438$ (1992).

13 Srouji, I. A., Andrews, P., Edwards, C. \& Lund, V. J. Patterns of presentation and diagnosis of patients with Wegener's granulomatosis: ENT aspects. The Journal of laryngology and otology 121, 653658, doi:10.1017/s0022215106005032 (2007).

14 Ahmad, I., Lee, W. C., Nagendran, V., Wilson, F. \& Shortridge, R. T. Localised Wegener's granulomatosis in otolaryngology: a review of six cases. ORL; journal for oto-rhino-laryngology and its related specialties 62, 149-155, doi:10.1159/000027736 (2000).

15 Takala, J. H., Kautiainen, H., Malmberg, H. \& Leirisalo-Repo, M. Wegener's granulomatosis in Finland in 1981-2000: clinical presentation and diagnostic delay. Scandinavian journal of rheumatology 37, 435-438, doi:10.1080/03009740802238366 (2008).

16 Finkielman, J. D. et al. ANCA are detectable in nearly all patients with active severe Wegener's granulomatosis. The American journal of medicine 120, 643.e649-614, doi:10.1016/j.amjmed.2006.08.016 (2007).

17 Federici, S. \& Gattorno, M. A practical approach to the diagnosis of autoinflammatory diseases in childhood. Best practice \& research. Clinical rheumatology 28, 263-276, doi:10.1016/j.berh.2014.05.005 (2014).

18 Ahmadi, N. et al. Cryopyrin-associated periodic syndromes: otolaryngologic and audiologic manifestations. Otolaryngology-head and neck surgery : official journal of American Academy of Otolaryngology-Head and Neck Surgery 145, 295-302, doi:10.1177/0194599811402296 (2011).

19 Migliori, G., Battisti, E., Pari, M., Vitelli, N. \& Cingolani, C. A shifty diagnosis: Cogan's syndrome. A case report and review of the literature. Acta otorhinolaryngologica Italica : organo ufficiale della Societa italiana di otorinolaringologia e chirurgia cervico-facciale 29, 108-113 (2009).

20 Saat, R. et al. MR imaging features of acute mastoiditis and their clinical relevance. AJNR. American journal of neuroradiology 36, 361-367, doi:10.3174/ajnr.A4120 (2015).

21 Dubrulle, F. et al. The round window sign: a sensitive sign to detect perilymphatic fistulae on delayed postcontrast 3D-FLAIR sequence. European radiology 30, 6303-6310, doi:10.1007/s00330-02006924-4 (2020). 
22 Kim, S. et al. A New MRI Grading System for Cervical Foraminal Stenosis Based on Axial T2Weighted Images. Korean journal of radiology 16, 1294-1302, doi:10.3348/kjr.2015.16.6.1294 (2015).

23 Kang, Y. et al. New MRI grading system for the cervical canal stenosis. AJR. American journal of roentgenology 197, W134-140, doi:10.2214/ajr.10.5560 (2011).

24 Breiman, L., Friedman, J., Olshen, R. \& Stone, C. Classification and regression trees. Wadsworth Int. Group 37, 237-251 (1984).

25 Lewis, R. J. in Annual meeting of the society for academic emergency medicine in San Francisco, California.

26 Teszler, C. B., Williams, M. T., Belange, G. \& Ayache, D. Labyrinthitis related to Wegener granulomatosis: magnetic resonance imaging findings. Otology \& neurotology : official publication of the American Otological Society, American Neurotology Society [and] European Academy of Otology and Neurotology 29, 721-722, doi:10.1097/mao.0b013e31815f665B (2008).

27 Yildirim, N., Arslanoglu, A. \& Aygun, N. Otologic and leptomeningeal involvements as presenting features in seronegative Wegener granulomatosis. American journal of otolaryngology 29, 147-149, doi:10.1016/j.amjoto.2007.04.007 (2008).

28 Casselman, J. W., Majoor, M. H. \& Albers, F. W. MR of the inner ear in patients with Cogan syndrome. AJNR. American journal of neuroradiology 15, 131-138 (1994).

29 Subramaniam, V., Ashkar, A. \& Rai, S. Cochlear Dysfunction in Chronic Otitis Media and Its Determinants. Iranian journal of otorhinolaryngology 32, 79-84, doi:10.22038/ijorl.2019.35045.2158 (2020).

30 Maroldi, R. et al. Computed tomography and magnetic resonance imaging of pathologic conditions of the middle ear. European journal of radiology 40, 78-93, doi:10.1016/s0720-048x(01)00376-x (2001).

31 Jung, T. T. \& Hanson, J. B. Classification of otitis media and surgical principles. Otolaryngologic clinics of North America 32, 369-383, doi:10.1016/s0030-6665(05)70139-0 (1999).

32 Sipilä, P. \& Karma, P. Inflammatory cells in mucoid effusion of secretory otitis media. Acta otolaryngologica 94, 467-472, doi:10.3109/00016488209128936 (1982).

33 Morris, P. Chronic suppurative otitis media. BMJ clinical evidence 2012 (2012).

34 Abdel Razek, A. A., Alvarez, H., Bagg, S., Refaat, S. \& Castillo, M. Imaging spectrum of CNS vasculitis. Radiographics : a review publication of the Radiological Society of North America, Inc 34, 873894, doi:10.1148/rg.344135028 (2014). 
35 Albayram, M. S., Wityk, R., Yousem, D. M. \& Zinreich, S. J. The cerebral angiographic findings in Cogan syndrome. AJNR. American journal of neuroradiology 22, $751-754$ (2001).

36 Antonios, N. \& Silliman, S. Cogan syndrome: an analysis of reported neurological manifestations. The neurologist 18, 55-63, doi:10.1097/NRL.0b013e31823fa3a0 (2012).

37 García Berrocal, J. R., Vargas, J. A., Vaquero, M., Ramón y Cajal, S. \& Ramírez-Camacho, R. A. Cogan's syndrome: an oculo-audiovestibular disease. Postgraduate medical journal 75, 262-264, doi:10.1136/pgmj.75.883.262 (1999).

38 Behringer, J., Ryan, M., Miller, M. \& Jaju, A. Magnetic resonance imaging findings in a patient with cryopyrin-associated periodic syndrome: A rare hereditary multi-system inflammatory disorder. The neuroradiology journa/ 32, 420-425, doi:10.1177/1971400919863712 (2019).

39 Mogi, G., Lim, D. J. \& Watanabe, N. Immunologic study on the inner ear. Immunoglobulins in perilymph. Archives of otolaryngology (Chicago, III. : 1960) 108, 270-275, doi:10.1001/archotol.1982.00790530006003 (1982).

40 Eliezer, M. et al. Detection of intralabyrinthine abnormalities using post-contrast delayed 3D-FLAIR MRI sequences in patients with acute vestibular syndrome. European radiology 29, 2760-2769, doi:10.1007/s00330-018-5825-0 (2019).

41 Attyé, A. et al. Endolymphatic hydrops imaging: Differential diagnosis in patients with Meniere disease symptoms. Diagnostic and interventional imaging 98, 699-706, doi:10.1016/j.diii.2017.06.002 (2017).

42 Yin, L. S., Kumar, G. \& Vijayananthan, A. J. E. J. o. R. E. Diffuse intracranial meningeal enhancement in Wegener's granulomatosis-a rare finding. 67, 5-8 (2008).

43 Tasali, N., Cubuk, R., Celik, L. \& Canbora, B. Atypical meningeal involvement in Wegener granulomatosis: MR imaging survey of a particular case. AJNR. American journal of neuroradiology 30 , E116, doi:10.3174/ajnr.A1645 (2009).

$44 \mathrm{Kim}, \mathrm{S}$. H. et al. ANCA-negative Wegener's granulomatosis with multiple lower cranial nerve palsies. Journal of Korean medical science 28, 1690-1696, doi:10.3346/jkms.2013.28.11.1690 (2013).

45 Liu, C. W. \& Hsu, Y. H. Wegener's granulomatosis that mimics nasopharyngeal cancer. Ci ji yi xue za zhi = Tzu-chi medical journal 28, 134-135, doi:10.1016/j.tcmj.2016.04.002 (2016).

46 Higuera-Ortiz, V. et al. Pachymeningitis in granulomatosis with polyangiitis: case series with earlier onset in younger patients and literature review. Clinical rheumatology 36, 919-924, doi:10.1007/s10067016-3520-6 (2017). 
47 Onyeuku, N. E., Balakrishnan, N. \& Cartwright, M. S. Granulomatosis with polyangiitis presenting with pachymeningitis. Journal of the neurological sciences 344, 208-209, doi:10.1016/j.jns.2014.06.052 (2014).

\section{Tables}

Table 1. MRI findings according to clinical diagnosis 


\begin{tabular}{|c|c|c|c|c|c|}
\hline & & $\begin{array}{l}\text { COM } \\
\text { group } \\
(\mathrm{n}= \\
24)\end{array}$ & $\begin{array}{l}\text { AIED/AID } \\
\text { group } \\
(\mathrm{n}=18)\end{array}$ & $\begin{array}{l}\text { Control } \\
\text { group } \\
(\mathrm{n}= \\
25)\end{array}$ & $P$-value \\
\hline \multirow{3}{*}{$\begin{array}{l}\text { Laterality of mastoid and middle ear } \\
\text { effusion }\end{array}$} & Absent & $0(0)$ & $5(27.8)$ & $\begin{array}{l}23 \\
230)\end{array}$ & \multirow{3}{*}{$\begin{array}{l}<.0001 * \\
\end{array}$} \\
\hline & Unilateral & $\begin{array}{l}21 \\
(87.5)\end{array}$ & $2(11.1)$ & $1(4.0)$ & \\
\hline & Bilateral & $\begin{array}{l}3 \\
(12.5)\end{array}$ & $11(61.1)$ & $1(4.0)$ & \\
\hline \multirow[t]{4}{*}{$\begin{array}{l}\text { Amount of mastoid and middle ear } \\
\text { effusion }\end{array}$} & $0 \%$ & $0(0)$ & $5(27.8)$ & $\begin{array}{l}25 \\
(100)\end{array}$ & \multirow[t]{4}{*}{$\begin{array}{l}< \\
0.0001 *\end{array}$} \\
\hline & $<50 \%$ & $\begin{array}{l}3 \\
(12.5)\end{array}$ & $3(16.7)$ & $0(0)$ & \\
\hline & $50-99 \%$ & $\begin{array}{l}5 \\
(20.8)\end{array}$ & $5(27.8)$ & $0(0)$ & \\
\hline & $100 \%$ & $\begin{array}{l}16 \\
(66.7)\end{array}$ & $5(27.8)$ & $0(0)$ & \\
\hline \multirow[t]{2}{*}{$\begin{array}{l}\text { Presence of any abnormalities in the } \\
\text { inner ear }\end{array}$} & Absent & $\begin{array}{l}18 \\
(75.0)\end{array}$ & $0(0)$ & $\begin{array}{l}24 \\
(96.0)\end{array}$ & \multirow[t]{2}{*}{$\begin{array}{l}< \\
0.0001 *\end{array}$} \\
\hline & Present & $\begin{array}{l}6 \\
(25.0)\end{array}$ & $18(100)$ & $1(4.0)$ & \\
\hline \multirow[t]{3}{*}{ Location of inner ear pathology } & Absent & $\begin{array}{l}18 \\
(75.0)\end{array}$ & $0(0)$ & $\begin{array}{l}24 \\
(96.0)\end{array}$ & \multirow[t]{3}{*}{ < $0.0001 *$} \\
\hline & Cochlea alone & $\begin{array}{l}4 \\
(16.7)\end{array}$ & $4(22.2)$ & $1(4.0)$ & \\
\hline & $\begin{array}{l}\text { More than } \\
\text { two subsites }\end{array}$ & $2(8.3)$ & $14(77.8)$ & $0(0)$ & \\
\hline \multirow[t]{3}{*}{ Laterality of inner ear pathology } & Absent & $\begin{array}{l}18 \\
(75.0)\end{array}$ & $0(0)$ & $\begin{array}{l}24 \\
(96.0)\end{array}$ & \multirow[t]{3}{*}{$\begin{array}{l}< \\
0.0001 *\end{array}$} \\
\hline & Unilateral & $2(8.3)$ & $2(11.1)$ & $0(0)$ & \\
\hline & Bilateral & $\begin{array}{l}4 \\
(16.7)\end{array}$ & $16(88.9)$ & $1(4.0)$ & \\
\hline \multirow[t]{3}{*}{ Presence of preFLAIR hyperintensity } & Absent & $\begin{array}{l}4 \\
(16.7)\end{array}$ & $0(0)$ & $\begin{array}{l}3 \\
(12.0)\end{array}$ & \multirow[t]{3}{*}{$0.005^{*}$} \\
\hline & Present & $2(8.3)$ & $7(38.9)$ & $0(0)$ & \\
\hline & Not available & $\begin{array}{l}18 \\
(75.0)\end{array}$ & $11(61.1)$ & $\begin{array}{l}22 \\
(88.0) \\
\end{array}$ & \\
\hline \multirow[t]{3}{*}{ Presence of postFLAIR enhancement } & Absent & $\begin{array}{l}16 \\
(66.7)\end{array}$ & $1(5.6)$ & $\begin{array}{l}11 \\
(44.0)\end{array}$ & \multirow[t]{3}{*}{ <.0001* } \\
\hline & Present & 6 & $15(83.3)$ & $1(4.0)$ & \\
\hline & Not available & $2(8.3)$ & $2(11.1)$ & $\begin{array}{l}13 \\
(52.0)\end{array}$ & \\
\hline \multirow[t]{5}{*}{ Degree of postFLAIR enhancement } & None & $\begin{array}{l}16 \\
(66.7)\end{array}$ & $2(11.1)$ & $\begin{array}{l}17 \\
(68.0)\end{array}$ & \multirow[t]{5}{*}{$\begin{array}{l}< \\
0.0001 *\end{array}$} \\
\hline & Minimal & $\begin{array}{l}5 \\
(20.8)\end{array}$ & $1(5.5)$ & $1(4.0)$ & \\
\hline & Mild & $1(4.2)$ & $2(11.1)$ & $0(0)$ & \\
\hline & Intensive & $0(0)$ & $12(66.8)$ & $0(0)$ & \\
\hline & Not available & $2(8.3)$ & $1(5.5)$ & $\begin{array}{l}7 \\
(28.0)\end{array}$ & \\
\hline Presence of postT1WI & Absent & 24 & $7(38.9)$ & 25 & $<$ \\
\hline
\end{tabular}




\begin{tabular}{|c|c|c|c|c|c|}
\hline & Present & $\begin{array}{l}(100) \\
0(0)\end{array}$ & $11(61.1)$ & $\begin{array}{l}(100) \\
0(0)\end{array}$ & $0.0001 *$ \\
\hline \multirow[t]{2}{*}{ Presence of cranial nerve involvement } & Absent & $\begin{array}{l}24 \\
(100)\end{array}$ & $15(83.3)$ & $\begin{array}{l}25 \\
(100)\end{array}$ & \multirow[t]{2}{*}{$0.0139 *$} \\
\hline & Present & $0(0)$ & $3(16.7)$ & $0(0)$ & \\
\hline \multirow[t]{2}{*}{ Presence of dura involvement } & Absent & 23 & $12(66.7)$ & 25 & \multirow[t]{2}{*}{$0.0009 *$} \\
\hline & Present & $1(4.2)$ & $6(33.3)$ & $0(0)$ & \\
\hline \multirow{2}{*}{$\begin{array}{l}\text { Presence of nasopharynx, external } \\
\text { auditory canal, and regional soft- } \\
\text { tissue involvement }\end{array}$} & Absent & 23 & $9(50)$ & & \multirow{2}{*}{$\begin{array}{l}<.0001 * \\
0.00\end{array}$} \\
\hline & Present & $1(4.2)$ & $9(50)$ & $0(0)$ & \\
\hline \multirow[t]{3}{*}{ Presence of RW sign on postFLAIR } & Absent & 17 & $5(27.8)$ & $17(68)$ & \multirow[t]{3}{*}{$0.0001^{*}$} \\
\hline & Present & 5 & $11(61.1)$ & $0(0)$ & \\
\hline & Not available & $2(8.3)$ & $2(11.1)$ & $8(32)$ & \\
\hline \multirow[t]{2}{*}{ Presence of RW sign on postT1WI } & Absent & 22 & $8(44.4)$ & 25 & \multirow{2}{*}{$\overline{0.0001 *}$} \\
\hline & Present & $2(8.3)$ & $10(55.6)$ & 0 & \\
\hline \multirow{3}{*}{$\begin{array}{l}\text { Presence of VA enhancement on } \\
\text { postFLAIR }\end{array}$} & Absent & 20 & $7(38.9)$ & $17(68)$ & \multirow[t]{3}{*}{$0.0001^{*}$} \\
\hline & Present & $2(8.3)$ & $9(50.0)$ & 0 & \\
\hline & Not available & $2(8.3)$ & $2(11.1)$ & $8(32)$ & \\
\hline
\end{tabular}

Data are presented as $\mathrm{n}(\%)$.

MRI, magnetic resonance imaging; COM, chronic otomastoiditis; AIED/AID, autoimmune/autoinflammatory inner ear disease; preFLAIR, pre-contrast fluid-attenuated inversion recovery image; postFLAIR, post-contrast fluid-attenuated inversion recovery image; postT1WI, post-contrast T1-weighted image; RW sign, round window sign; VA, vestibular aqueduct

* Statistical significance was set at $P<0.05$.

Table 2. Diagnostic performance of the two decision-making trees 


\begin{tabular}{|c|c|c|c|c|}
\hline & $\begin{array}{l}\mathrm{SN}(\%) \\
(95 \% \mathrm{CI})\end{array}$ & $\begin{array}{l}\text { SP (\%) } \\
(95 \% \mathrm{CI})\end{array}$ & $\begin{array}{l}\text { PPV (\%) } \\
(95 \% \mathrm{CI})\end{array}$ & $\begin{array}{l}\text { NPV (\%) } \\
(95 \% \text { CI) }\end{array}$ \\
\hline \multicolumn{5}{|l|}{ The first decision-making tree ${ }^{a}$} \\
\hline \multirow{2}{*}{$\begin{array}{l}\text { (COM group) vs. (AIED/AID, control } \\
\text { groups) }\end{array}$} & 100 & $\overline{93}$ & 88.9 & 100 \\
\hline & $(0-100)$ & $\begin{array}{l}(38.8- \\
85.4)\end{array}$ & $\begin{array}{l}(60.5- \\
77.0)\end{array}$ & $(0-100)$ \\
\hline \multirow{2}{*}{$\begin{array}{l}\text { (AIED/AID group) vs. (COM, control } \\
\text { groups) }\end{array}$} & 55.6 & 100 & 100 & 86 \\
\hline & $\begin{array}{l}(32.6- \\
78.5)\end{array}$ & $(0-100)$ & $(0-100)$ & $(77-95)$ \\
\hline \multirow{2}{*}{$\begin{array}{l}\text { (Control group) vs. (COM, AIED/AID } \\
\text { groups) }\end{array}$} & 100 & 88.1 & 88.3 & 100 \\
\hline & $(0-100)$ & $\begin{array}{l}(78.3- \\
97.9)\end{array}$ & $(70-97)$ & $(0-100)$ \\
\hline \multicolumn{5}{|l|}{ The second decision-making tree ${ }^{\mathrm{b}}$} \\
\hline \multirow{2}{*}{$\begin{array}{l}\text { (COM group) vs. (AIED/AID, control } \\
\text { groups) }\end{array}$} & 22.7 & $\overline{91.3}$ & 71.4 & 55.3 \\
\hline & $\begin{array}{l}(52.1- \\
40.2)\end{array}$ & $(80.0-100)$ & $(38.0-100)$ & $\begin{array}{l}(39.4- \\
71.1)\end{array}$ \\
\hline \multirow{2}{*}{$\begin{array}{l}\text { (AIED/AID group) vs. (COM, control } \\
\text { groups) }\end{array}$} & 40 & 94.5 & 66.7 & 92.8 \\
\hline & $(0-83.0)$ & $(92.7-100)$ & $(13.3-100)$ & $(85.1-100)$ \\
\hline \multirow{2}{*}{$\begin{array}{l}\text { (Control group) vs. (COM, AIED/AID } \\
\text { groups) }\end{array}$} & 94.4 & 33.3 & 48.6 & 90 \\
\hline & $(83.9-100)$ & $\begin{array}{l}(15.5- \\
51.1)\end{array}$ & $\begin{array}{l}(32.0- \\
65.1)\end{array}$ & $(71.4-100)$ \\
\hline
\end{tabular}

SN, sensitivity; SP, specificity; PPV, positive predictive value; NPV, negative predictive value; CI, confidence interval; COM, chronic otomastoiditis; AIED/AID, autoimmune/autoinflammatory inner ear disease.

${ }^{\mathrm{a}}$ The first decision-making tree used two nodes for the amount of effusion and presence of inner ear enhancement on post-contrast T1-wegithed image.

${ }^{\mathrm{b}}$ The second decision-making tree used two nodes of the degree

of inner ear enhancement on post-contrast fluid-attenuated inversion recovery image (mild-tointense and none-to-minimal, respectively).

\section{Figures}




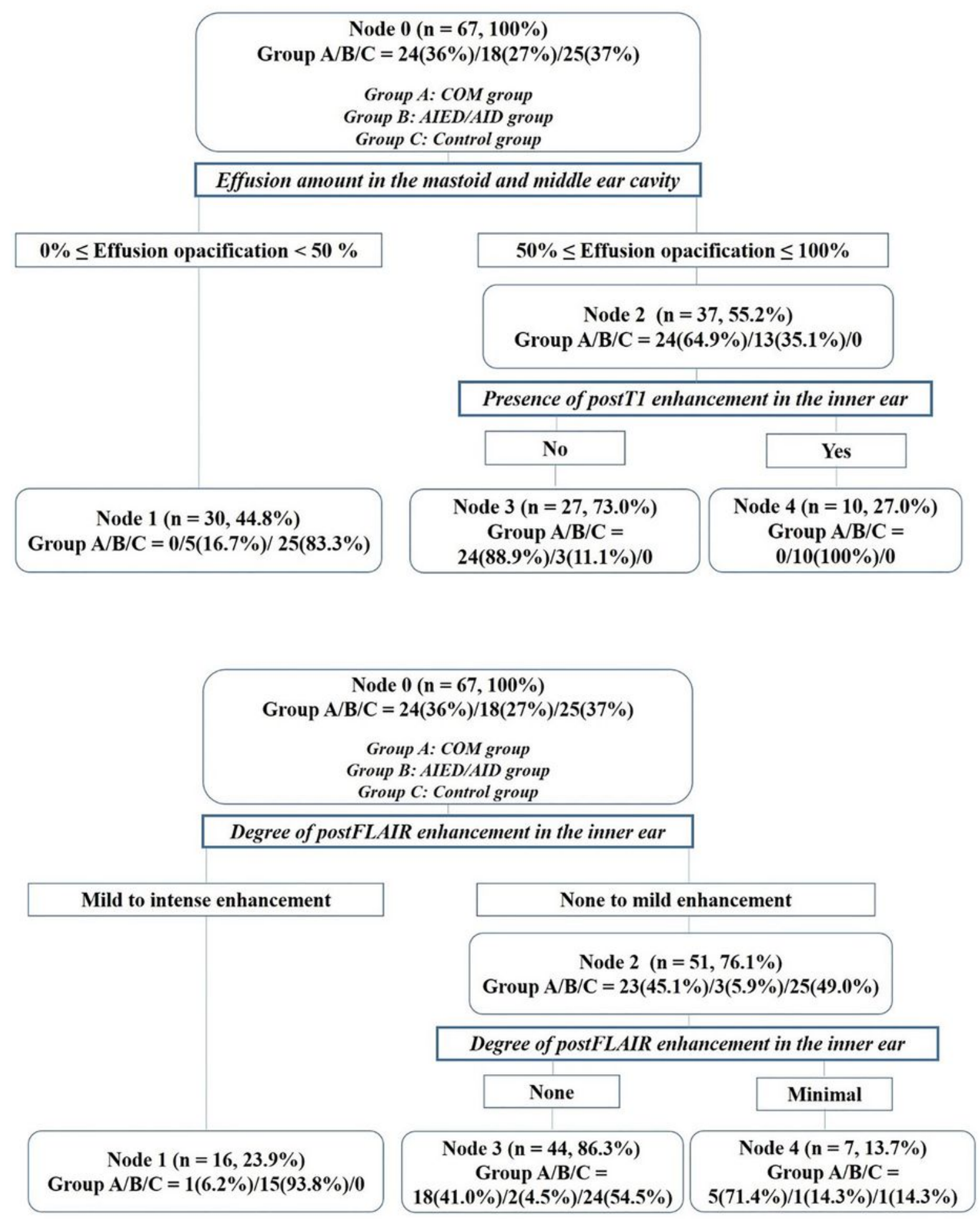

\section{Figure 1}

Classification and regression tree analysis (CART) results. The first decision-making tree (A) uses two nodes of the amount of effusion in the mastoid and middle ear cavity and the presence of enhancement in the inner ear structures on post-contrast T1-weighted images (postT1WI). The second decision-making tree (B) utilized the degree of enhancement in the inner ear structures on post-contrast FLAIR images (postFLAIR) as the partitioning node. Group A was the chronic otomastoiditis (COM) group, group B was 
the autoimmune inner ear disease and autoinflammatory inner ear disease (AIED/AID) group, and group $\mathrm{C}$ was the control group. The details regarding the tree are explained in the Results section
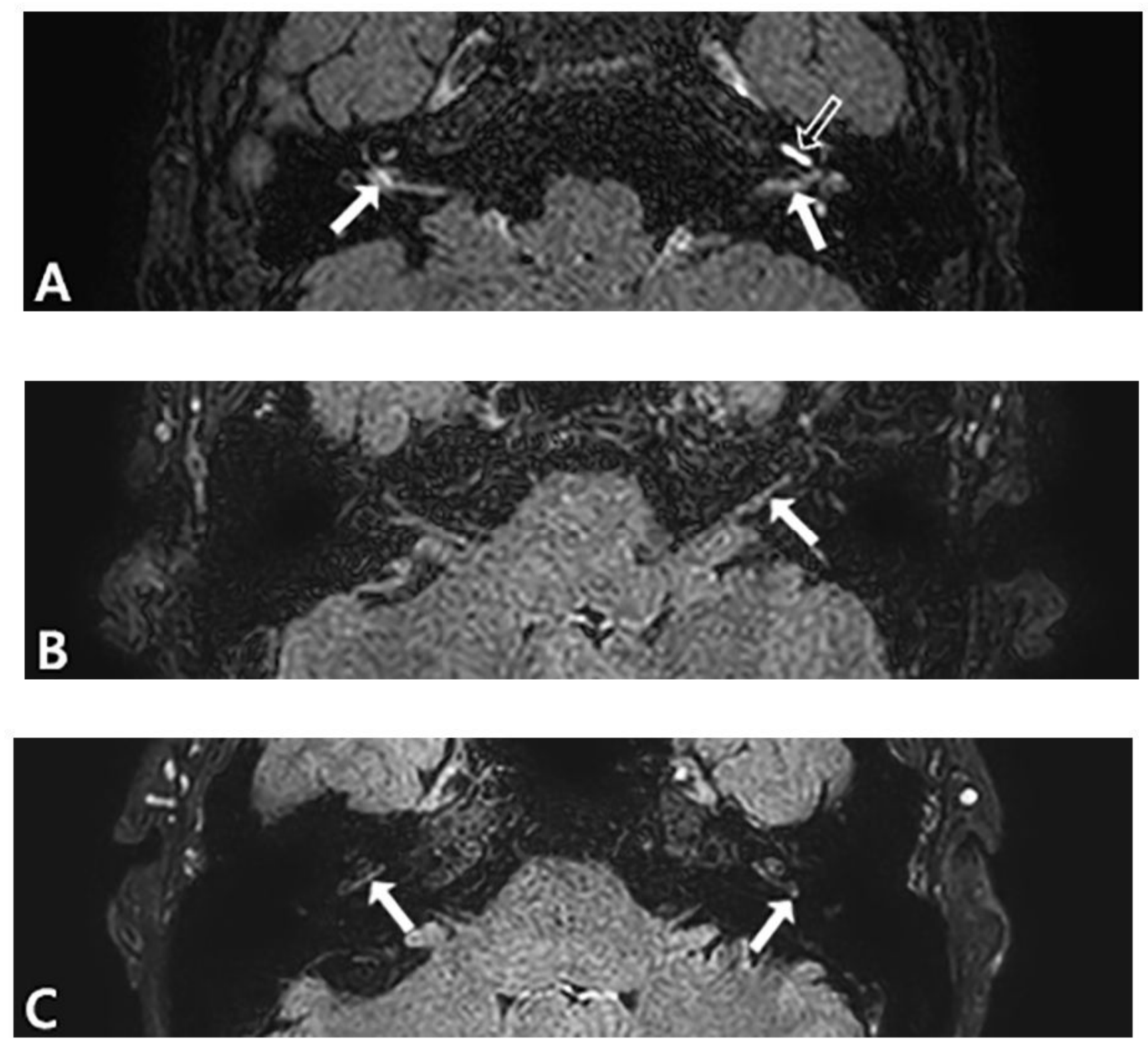

\section{Figure 2}

Representative cases of CINCA syndrome. (A) A 13-year-old male diagnosed with CINCA syndrome presented with intense inner ear enhancement in cochlea (empty arrow at left cochlea) and strong enhancement of bilateral cochlear nerves (arrows) on post-contrast FLAIR image (postFLAIR). (B) A 33year-old female diagnosed with CINCA syndrome presented with strong enhancement of left cochlear 
nerve on postFLAIR (arrow) compared to enhancement of the cochlea. (C) A 38-year-old female diagnosed with CINCA syndrome presented with postFLAIR-enhancement of bilateral cochlea (arrows), but absence of enhancement of the cochlear nerve

\section{Supplementary Files}

This is a list of supplementary files associated with this preprint. Click to download.

- FigureS1A.tif

- FigureS1B.tif

- FigureS1C.tif

- FigureS1D.tif

- FigureS2.tif

- FigureS3A.tif

- Figures3B.tif

- FigureS3C.tif

- FigureS3D.tif

- FigureS4A.tif

- Figures4B.tif

- FigureS4C.tif

- FigureS4D.tif

- FigureS5A.tif

- FigureS5B.tif

- Figures6.tif

- SupplementalData.docx 